\title{
THERMAL-STRUCTURAL OPTIMIZATION OF INTEGRATED CRYOGENIC PROPELLANT TANK CONCEPTS FOR A REUSABLE LAUNCH VEHICLE ${ }^{1}$
}

\author{
Theodore F. Johnson ${ }^{\square}$ and W. Allen Waters ${ }^{+}$ \\ NASA Langley Research Center, Hampton, VA 23681-2199 \\ Thomas N. Singer ${ }^{\dagger}$ and Raphael T. Haftka ${ }^{\square 0}$ \\ University of Florida, Department of Mechanical and Aerospace Engineering \\ Gainesville, FL 32611-6250
}

\begin{abstract}
A next generation reusable launch vehicle (RLV) will require thermally efficient and light-weight cryogenic propellant tank structures. Since these tanks will be weight-critical, analytical tools must be developed to aid in sizing the thickness of insulation layers and structural geometry for optimal performance. Finite element method (FEM) models of the tank and insulation layers were created to analyze the thermal performance of the cryogenic insulation layer and thermal protection system (TPS) of the tanks. The thermal conditions of ground-hold and re-entry/soakthrough for a typical RLV mission were used in the thermal sizing study. A general-purpose nonlinear FEM analysis code, capable of using temperature and pressure dependent material properties, was used as the thermal analysis code. Mechanical loads from ground handling and proof-pressure testing were used to size the structural geometry of an aluminum cryogenic tank wall. Nonlinear deterministic optimization and reliability optimization techniques were the analytical tools used to size the geometry of the isogrid stiffeners and thickness of the skin. The results from the sizing study indicate that a commercial FEM code can be used for thermal analyses to size the insulation thicknesses where the temperature and pressure were varied. The results from the structural sizing study show that using combined deterministic and reliability optimization techniques can obtain alternate and lighter designs than the designs obtained from deterministic optimization methods alone.
\end{abstract}

\section{INTRODUCTION}

The development and fabrication of reusable cryogenic tanks is one of the significant technical challenges in the development of an operable RLV [1,
2]. Large (30-ft. dia.) reusable cryogenic tanks will be required to contain the $\mathrm{LH}_{2}$ and $\mathrm{LOx}$ for an RLV. The development of flight-weight reusable cryogenic propellant tanks is critical for an RLV because the tanks, as shown in Figure 1 for a generic RLV, may comprise as much as 35 percent of the dry structural weight of the vehicle and occupy 70 percent of the internal volume of the vehicle. The cryogenic tanks of an RLV must not only function as pressure vessels at cryogenic temperatures, but the tanks also must carry primary structural loads and support the thermal protection system (TPS). An example of a section of an integrated tank system design is shown in Figure 2. In this concept, an aluminum 2219-T87 (Al 2219) wall with cryogenic insulation (CI) serves as the pressure vessel, primary structure, and TPS support structure. Analytical tools must be developed to size the throughthe-thickness insulation and structural geometry of the tank structures. With these tools, various combinations of insulation concepts and tank structures could be efficiently analyzed and optimized in thermal and structural trade studies to develop robust and lightweight integrated structures for an RLV.

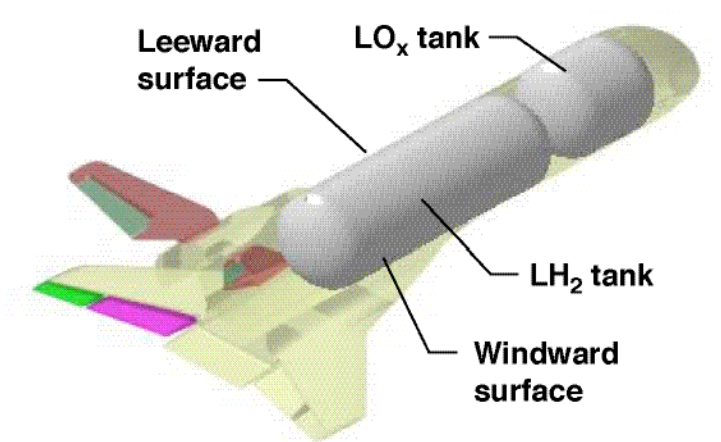

Figure 1. A generic $\mathrm{RLV}$ with an aft-located $\mathrm{LH}_{2}$ tank.

${ }^{1}$ Copyright 2004 by the American Institute of Aeronautics and Astronautics, Inc. No copyright is asserted in the United States under Title 17, U.S. Code. The U.S. Government has a royalty-free license to exercise all rights under the copyright claimed herein for Governmental purposes. All other rights are reserved by the copyright owner.

Aerospace Engineer, Mechanics and Durability Branch. Member, AIAA.

+ Aerospace Engineer, Lockheed-Martin Corporation, Hampton, VA.

† Graduate Student, Dept. of Mechanical and Aerospace Engineering, University of Florida. Student Member, AIAA.

प Professor, Dept. of Mechanical and Aerospace Engineering, University of Florida. Senior Fellow, AIAA. 
The objective of this paper is to present the analytical tools that were developed and results for the thermal sizing of insulation for the CI and TPS, and structural sizing of the geometry of the isogrid stiffeners and skin thickness for an aluminum cryogenic propellant tank of an RLV. A nonlinear finite element method (FEM) analysis program capable of performing thermal analyses using temperature and pressure dependent material properties was utilized to analyze combinations of candidate CI and TPS. Nonlinear structural analysis, deterministic optimization techniques, and reliability optimization techniques were used to size the isogrid stiffening geometry and skin thickness for an aluminum cryogenic tank. The analytical tools, methods, and results of the thermal sizing study will be presented first, followed by the analytical tools, methods, and results of the structural sizing study. At the end of the paper, the results from both sets of analyses will be combined.

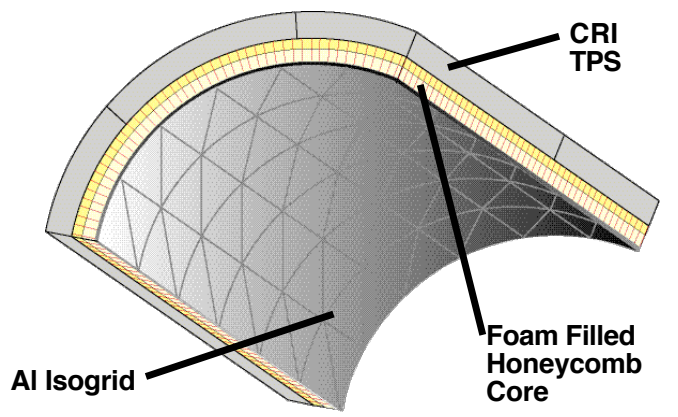

Figure 2. An example of an RLV metallic integrated tank concept with an aluminum isogrid tank wall, foam-filled honeycomb insulation, and conformable reusable insulation (CRI) TPS.

\section{THERMAL SIZING STUDY}

A thermal sizing study of two integrated tank design concepts was conducted to develop the insulation thickness of the CI and TPS and to maximize the thermal efficiency for two load cases: 1) ground-hold and 2) re-entry/soak-through. Nonlinear transient heat transfer analyses for the two cases were performed using ABAQUS, a nonlinear FEM analysis code.

\section{Approach}

The criteria used for sizing the thickness of the CI and TPS for an $\mathrm{LH}_{2}$ tank for the ground-hold case were to: maintain propellant quality (average heat flux through-the-thickness less than $45 \mathrm{BTU} / \mathrm{Hr}-\mathrm{ft}^{2}{ }^{2}$ ), maintain a constant temperature of $-423^{\circ} \mathrm{F}$ at the inner tank wall, prevent frost build-up and air liquefaction on the surface of the CI (exterior surface temperature greater than $32^{\circ} \mathrm{F}$ ), and maintain temperatures above the minimum use temperatures of the various materials used in the tank wall, CI, adhesives, and TPS. The only criteria for the re-entry/soak-through case were to not exceed the maximum, or fall below the minimum, use temperatures of the materials through-the-thickness. Temperatures may decrease for the re-entry/soak-through case due to aerothermal cooling.

The results from both thermal analyses cases were evaluated to determine if the temperature limits of the materials were violated. If a temperature in a layer was near the maximum or minimum temperature limit of the material for either the ground-hold or re-entry/soakthrough analyses, the insulation thicknesses of the CI or TPS were decreased or increased accordingly and both analyses repeated. The thickness of the tank wall, adhesive layers, coatings, and blanket over wrap, were held constant.

\section{Insulation Concepts}

Two design concepts for insulation systems were analyzed in the thermal sizing study and are listed in Table 1. Temperature limits for these materials are shown in Figure 3, and the densities and temperature limits are listed in Table 2. Concept I had an Al 2219 metallic alloy tank wall with a hybrid CI bonded to the external surface with Lord $212^{\mathrm{TM}}$ adhesive. The hybrid CI was a layer of PDL-1034 CI and a layer of TEEK CI [3]. In an actual RLV CI, the foam of the hybrid CI would be inside a honeycomb core to increase the tension strength, bondline strength, and robustness of the CI. Unfortunately, thermal properties for the hybrid $\mathrm{CI}$ in honeycomb core were not available for this study. The neat CI thermal properties were used instead. Conformable reusable insulation (CRI) TPS was bonded to the hybrid CI with RTV-560 adhesive. The CRI consisted of CRI batting insulation over-wrapped with the same fabric from an advanced flexible reusable insulation (AFRSI) TPS. The external surface or outer mold-line (OML) was thicker than the inner surface or inner mold-line (IML). The OML of the AFRSI fabric was coated with C-9 ceramic coating. Concept II had the same tank wall and CI configuration as Concept I, but had a coated flexible reusable surface insulation (FRSI) TPS bonded to the external surface of the CI with RTV-560. The OML of the FRSI was coated with hardened FRSI (HFRSI). Concept I was used on the windward or bottom surface, as shown in Figure 1, and Concept II was used on the leeward or upper surface.

\section{Thermal Load Cases}

Ground-hold and re-entry/soak-through load cases provided the temperature conditions to size the thickness of the CI and the internal insulation of the TPS. The ground-hold condition case was developed to simulate the point in time when the vehicle is on the launch pad being filled with fuel just prior to launch. The ascent phase was not analyzed. The re-entry and soak-through conditions are combined because these conditions take place consecutively during the return to Earth phase of the vehicle. During re-entry, the exterior 
surface of the vehicle experiences the highest aerothermal heating which was greater than the ascent phase. At soak-through, the TPS releases the heat energy that was absorbed during re-entry to the atmosphere and internal structure. Thus, the internal structure will possibly experience the maximum temperature after the vehicle has landed [4].

Table 1. Concepts, initial thicknesses, and upper and lower limits used in the thermal sizing study.

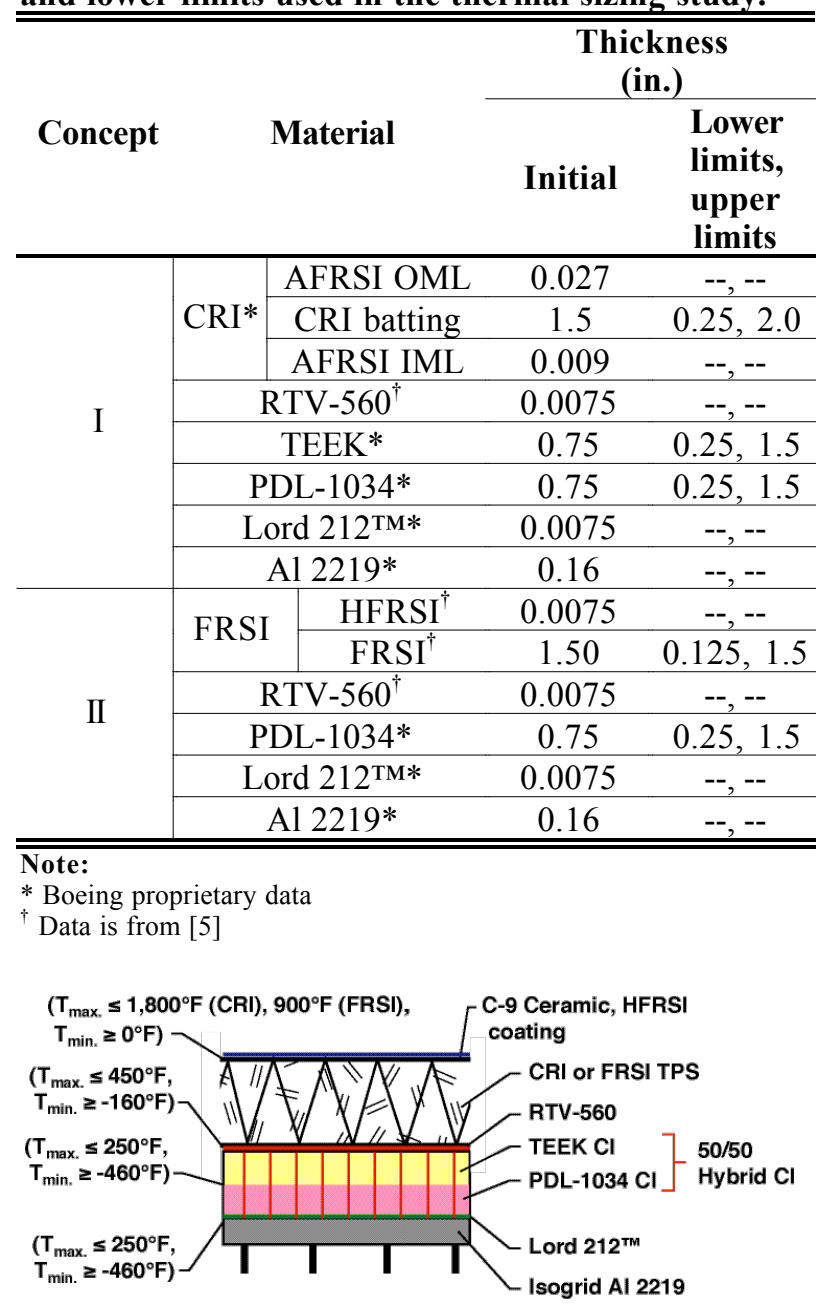

Figure 3. Graphical depiction of the tank crosssection with minimum and maximum use temperature limits for the respective materials used in the thermal sizing study.

The thermal boundary conditions in the model are depicted in Figure 4. A constant temperature of $-423^{\circ} \mathrm{F}$ was maintained on the inner tank wall surface for the ground-hold case. An adiabatic thermal boundary condition was assumed at the inner tank wall surface due to the large volume of the tank for the reentry/soak-through case. Natural convection to air was the boundary condition used on the exterior surface for the ground-hold case. A convection coefficient of 2.4
BTU/Hr.-ft. ${ }^{2}{ }^{\circ} \mathrm{F}[4]$ was used. Radiation to atmosphere was the boundary condition used for the re-entry/soakthrough case with a heat flux load from the aerothermal loading. The normalized windward and leeward heat flux loads and pressure profiles for the re-entry/soakthrough case are shown in Figure 5. The heat fluxes are normalized with respect to the maximum windward heat flux.

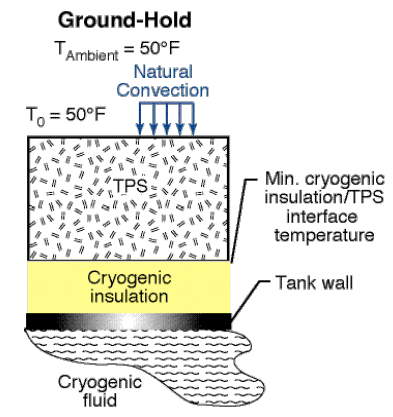

(a)

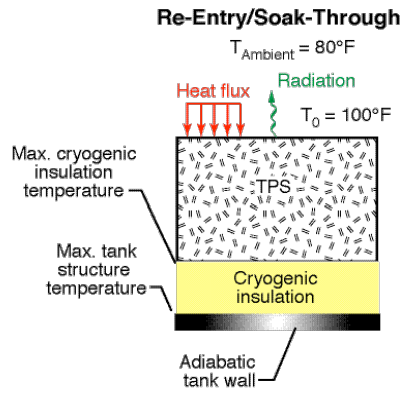

(b)
Figure 4. Two cases for the thermal sizing study: (a) ground-hold and (b) re-entry/soak-through.

Table 2. Density and temperature limits of the material used in the thermal sizing study.

\begin{tabular}{|c|c|c|c|c|}
\hline & Material & Density & Tempe & ure $\left({ }^{\circ} \mathbf{F}\right)$ \\
\hline & & (lbs./in. $\left.{ }^{3}\right)$ & Min. & Max. \\
\hline & AFRSI OML & 0.03484 & -200 & 2,600 \\
\hline CRI & CRI batting & 0.006134 & -200 & 1,800 \\
\hline & AFRSI IML & 0.03484 & -200 & 2,600 \\
\hline FP SI & HFRSI & 0.05613 & -200 & 1,160 \\
\hline ГNग & FRSI & 0.003125 & -200 & 900 \\
\hline & RTV-560 & 0.05093 & -160 & 550 \\
\hline & TEEK & 0.001157 & -450 & 450 \\
\hline & PDL-1034 & 0.001447 & -450 & 250 \\
\hline & ord $212^{\mathrm{TM}}$ & 0.03935 & -450 & 250 \\
\hline & Al 2219 & 0.1030 & -450 & 250 \\
\hline
\end{tabular}

\section{ABAQUS Analysis}

A one-dimensional FEM model was used to model the through-the-thickness layers of the tank wall. A nonlinear transient heat transfer analysis was employed for the following studies: mesh convergence, groundhold, and re-entry/soak-through. The model was analyzed in increments of $10 \mathrm{sec}$. The mesh convergence study was reported in a previous paper by Smeltzer et al. [6].

The initial wall designs had a total thickness of 3.2 inches. Mesh patterns incorporating 261 nodes and 260 elements for Concept I and 221 nodes and 220 elements for Concept II were used. The one-dimensional solid link element, DC1D2 in ABAQUS, was used in all the models analyzed. The elements were oriented in the 3 
area of $1.0 \mathrm{in}^{2}$ in the yz-plane. The boundary conditions varied as required by the particular analyses being performed.

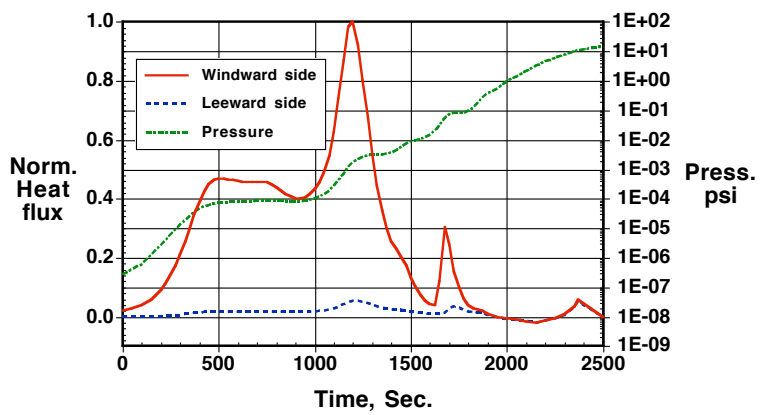

Figure 5. The normalized heat fluxes on the windward and leeward centerlines of the vehicle and exterior atmospheric pressure during re-entry used in the thermal sizing study.

The thermal conductivities for CRI and FRSI were both temperature and pressure dependent, however, the specific heats were only temperature dependent. Temperature and pressure dependence effected the thermal conductivity by reducing the thermal conductivity as the pressure and temperature decreased. The thermal conductivities and specific heats of the other materials, except for the coatings, were only temperature dependent. The coatings affected the value of the emissivities. The emissivities were held at constant values of 0.8 and 0.9 for Concepts I and II respectively due to constraints in ABAQUS, even though the emissivities were temperature dependent.

The ground-hold case had an initial isothermal temperature of $50^{\circ} \mathrm{F}$ with an ambient air temperature of $50^{\circ} \mathrm{F}$ to simulate a launch on a cold day. A temperature condition of $-423^{\circ} \mathrm{F}$ was imposed on the inner tank wall. An initial isothermal temperature of $100^{\circ} \mathrm{F}$ through-the-thickness was imposed on the models at the start of the re-entry/soak-through analysis case to simulate a warm initial temperature. An ambient temperature condition of $80^{\circ} \mathrm{F}$ was imposed on the exterior node of the models to simulate a $80^{\circ} \mathrm{F}$ temperature at the landing site.

\section{$\underline{\text { Results }}$}

The thermal analysis and sizing results for both concepts of the ground-hold and re-entry/soak-through cases are presented in Figures 6 through 13, and Tables 3 and 4 . The variation of temperature results throughthe-thickness of the tank wall for both concepts is plotted in the figures for selected time steps until steady-state temperatures for the ground-hold case were reached or a clear decrease in temperature for the reentry/soak-through case began. The iterative results for the insulation thickness and areal weights are listed in Table 3. The through-the-thickness layers depicted in Figure 3 are indicated at the top of the plots in Figures
$6,8,10$, and 12. Plots of the temperature results at the nodal interfaces at the top of each layer are shown in Figures 8, 10, 12, and 14 .

In Table 3 , the final thickness results from ABAQUS are listed for Concepts I and II. The through-the-thickness temperatures are listed in Table 4. Eight iterations were required to obtain a feasible solution for Concept I and six iterations were required for Concept II. The final areal weights for the insulation are $0.01112 \mathrm{lbs} . /$ in. $^{2}$ and $0.004093 \mathrm{lbs} . /$ in. $^{2}$ for Concepts I and II respectively.

Table 3. CI and TPS insulation thickness and total weight results.

\begin{tabular}{c|cccc}
\hline \hline Concept & $\begin{array}{c}\text { Iter. } \\
\text { no. }\end{array}$ & $\begin{array}{c}\text { CI } \\
\text { (in.) }\end{array}$ & $\begin{array}{c}\text { TPS } \\
\text { (in.) }\end{array}$ & $\begin{array}{c}\text { Areal wt. } \\
\text { (lbs./in. }\end{array}$ \\
\hline \multirow{4}{*}{ I } & 1 & 1.5 & 1.5 & 0.01309 \\
\cline { 2 - 5 } & 2 & 1.2 & 1.2 & 0.01086 \\
\cline { 2 - 5 } & 3 & 1.0 & 1.4 & 0.01182 \\
\cline { 2 - 5 } & 4 & 0.8 & 1.4 & 0.01156 \\
\cline { 2 - 5 } & 5 & 0.8 & 1.3 & 0.01095 \\
\cline { 2 - 5 } & 6 & 0.7 & 1.3 & 0.01143 \\
\cline { 2 - 5 } & 7 & 0.7 & 1.35 & 0.01112 \\
\hline \multirow{4}{*}{ II } & 1 & 1.5 & 1.5 & 0.007739 \\
\cline { 2 - 5 } & 2 & 1.8 & 0.25 & 0.004223 \\
\cline { 2 - 5 } & 3 & 1.6 & 0.125 & 0.003963 \\
\cline { 2 - 5 } & 4 & 1.7 & 0.125 & 0.004093 \\
\hline \hline
\end{tabular}

Note:

CI thickness is evenly divided between the PDL-1034 and TEEK. TPS thickness is the CRI batting or FRSI for Concepts I and II respectively.

$\uparrow$ The areal weights for Concept I includes the areal weights of the Lord $212^{\mathrm{TM}}$, CI, RTV-560, AFRSI IML, CRI batting, AFRSI OML, and C-9 coating. The areal weights for Concept II includes the areal weights of the Lord $212^{\mathrm{TM}}$, CI, RTV-560, FRSI, and HFRSI.

The ground-hold results plotted in Figures 6 through 8 indicate that both concepts will operate efficiently and effectively with 0.7 -in.-thick and 1.7-in.thick CI for Concepts I and II, respectively. The results in Figures 6 and 8 display how the concepts cooled over time with a $-423^{\circ} \mathrm{F}$ tank wall inner surface. A steady-state temperature condition was achieved for Concept I by $\mathrm{t}=6,000 \mathrm{sec}$. in Figure 7, with a surface temperature of $38.18^{\circ} \mathrm{F}$. Concept II reached a steadystate temperature condition by $\mathrm{t}=5,000 \mathrm{sec}$. in Figure 9 , and had a surface temperature of $35.42^{\circ} \mathrm{F}$. Both concepts maintained a temperature above $-160^{\circ} \mathrm{F}$ at the RTV-560 bondline and the upper surface should not develop frost (the exterior temperature is greater than $32^{\circ} \mathrm{F}^{\square}$ in Figures 6 through 9). The maximum average through-the-thickness heat flux was 28.4 BTU/Hr.-ft. ${ }^{2}$ and 33.9 BTU/Hr.-ft. ${ }^{2}$ for Concepts I and II,

$\square \square$ A surface temperature of $32^{\circ} \mathrm{F}$ does not ensure that frost buildup will not occur. Other factors such as humidity, ambient air temperature, radiation, and atmospheric pressure dictate whether frost will form on a surface. The boundary conditions and initial temperatures imposed in this study are conservative and will 4

\section{American Institute of Aeronautics and Astronautics}


respectively. Both concepts had an average heat flux less than the maximum limit of $45 \mathrm{BTU} / \mathrm{Hr} .-\mathrm{ft}^{2}{ }^{2}$ to prevent $\mathrm{LH}_{2}$ boil-off.

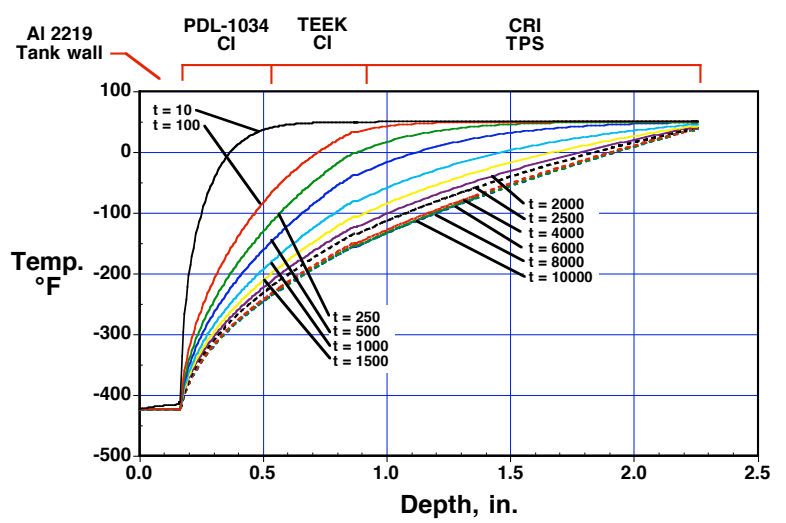

Figure 6. Through-the-thickness temperature results for Concept I with CRI TPS for the ground-hold case.

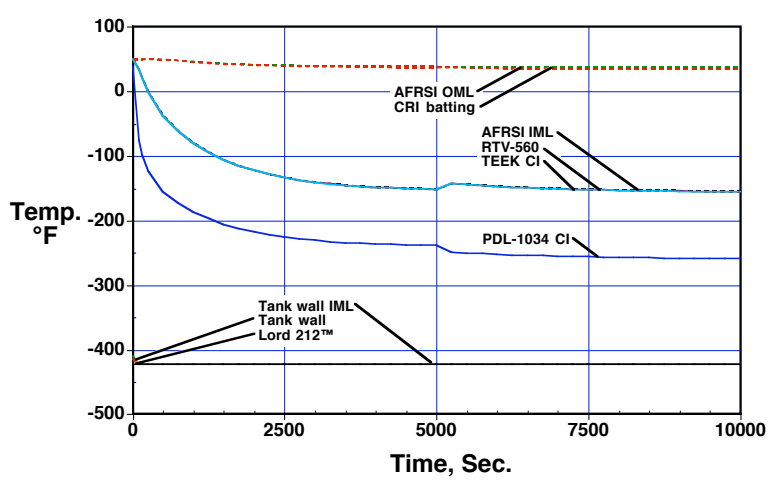

Figure 7. Temperature results at the upper surface of each layer of Concept I with CRI TPS for the ground-hold case.

The re-entry/soak-through temperature results from ABAQUS are plotted in Figures 10 through and 13. The propagation of the temperature pulse through-thethickness is shown in Figures 10 and 12 for Concepts I and II, respectively. The results in Figure 11 indicate that Concept I achieved maximum temperature conditions at the critical layers (tank wall and CI to TPS interface) at approximately 2,100 sec. to 2,300 sec. The results in Figure 13 indicate that Concept II achieved the maximum temperature conditions at the same critical layers at approximately 1,200 sec. to $1,400 \mathrm{sec}$. The maximum temperature on the exterior surface was $1,676^{\circ} \mathrm{F}$ at $1,200 \mathrm{sec}$. for Concepts I and $542.6^{\circ} \mathrm{F}$ at $1,200 \mathrm{sec}$. for Concepts II. The throughthe-thickness temperatures began to decrease in Figure 11 at 2,300 sec. for Concept I and in Figure 13 at 2,900 sec. for Concept II. The through-the-thickness temperatures, listed in Table 4, were below the maximum use temperatures of the materials shown in Figure 3 for both concepts. There was also a significant decrease in temperature on the upper nodes for both concepts in Figures 10 and 12. This was due to simulated aerothermal cooling as the vehicle passed through the atmosphere.

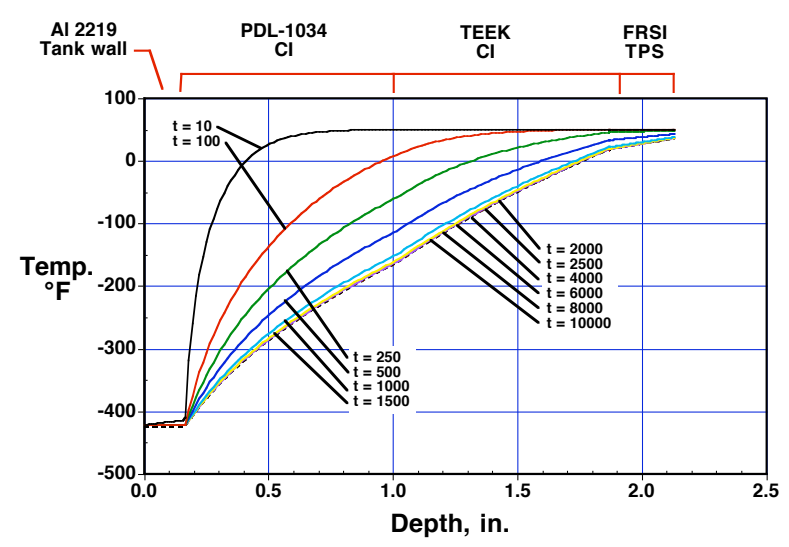

Figure 8. Through-the-thickness temperature results for Concept II with FRSI TPS for the ground-hold case.

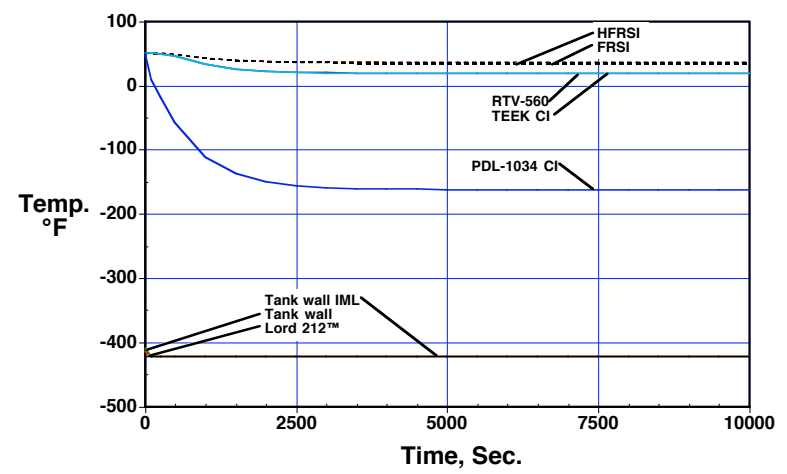

Figure 9. Temperature results at the upper surface of each layer of Concept II with FRSI TPS for the ground-hold case.

Concept I required a greater number of iterations than Concept II to achieve an optimal design. The additional iterations were precipitated from the CI and TPS working as a system during the ground-hold and re-entry/soak-through analyses. The TPS acted as a cryogenic insulator during ground-hold and the CI acted as a high temperature insulator during re-entry/soakthrough. As the insulation thickness was reduced, low and high temperature limits were violated, and the insulation thicknesses had to be revised. The minimum temperature at the RTV-560 bondline and prevention of frost on the exterior surface dominated the sizing of the insulation for the ground-hold case for Concept I. The prevention of frost and the maximum average heat flux through-the-thickness for the ground-hold case dictated the thickness of the CI for Concept II while the FRSI was driven to the minimum thickness allowed. Since the FRSI was at its minimum thickness, the FRSI did 5

\section{American Institute of Aeronautics and Astronautics}


which required Concept II to have almost twice as much CI as Concept I.

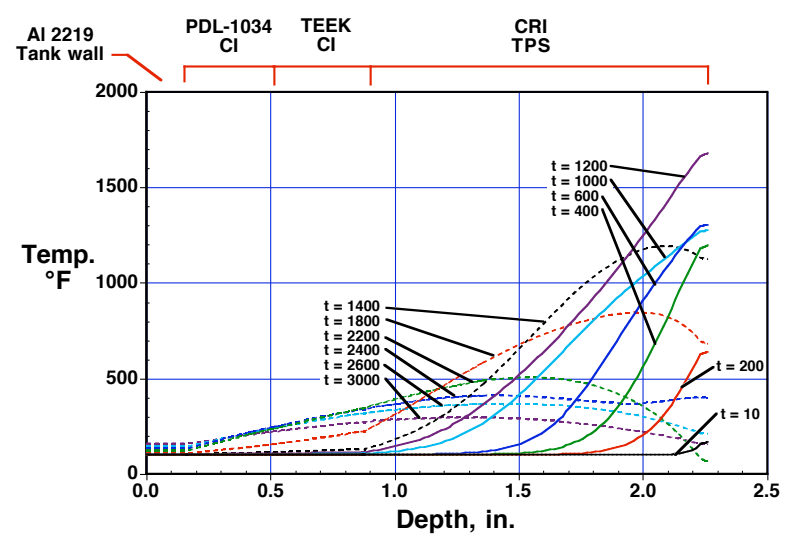

Figure 10. Through-the-thickness temperature results for Concept I with CRI TPS for the reentry/soak-through case.

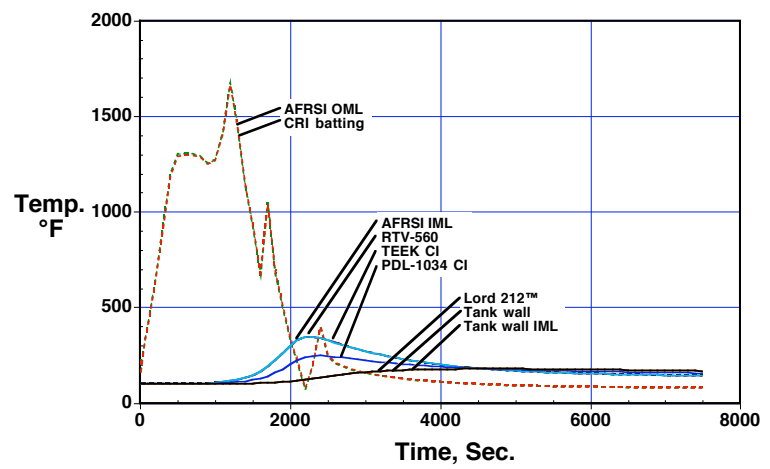

Figure 11. Temperature results at the upper surface of each layer of Concept I with CRI TPS for the reentry/soak-through case.

\section{STRUCTURAL SIZING STUDY}

The skin thicknesses and isogrid geometry of the tank wall were sized for an aluminum tank using the pressure and mechanical loads from two conditions: proof-pressure testing and ground handling. Before a tank is brought into service, proof-pressure testing will be performed at 1.05 times the maximum pressure. Only the barrel section of the cryogenic tank was analyzed in this study to simplify the analyses.

\section{Sizing Approach}

The design and optimization of metallic stiffened shells for buckling and stress constraints is characterized by a large number of local optima. Because the design space is characterized by multiple local optima, global optimization plays an important role. A deterministic optimization scheme was developed using the divide rectangles (DIRECT) [7, 8] global optimization algorithm in conjunction with PANDA2 [9], generating a number of feasible or nearly feasible designs for reliability analysis using Monte Carlo simulation (MCS).

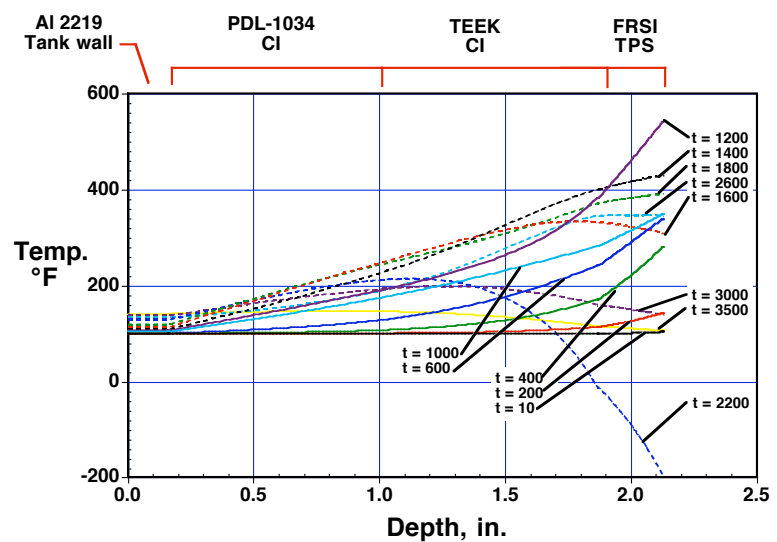

Figure 12. Through-the-thickness temperature results for Concept II with FRSI TPS for the reentry/soak-through case.

Table 4. Results for minimum and maximum temperatures at the upper surface of each layer.

\begin{tabular}{c|ccc}
\hline \hline \multirow{4}{*}{ Concept } & Layer & $\begin{array}{c}\text { Ground- } \\
\text { hold } \\
\left.\mathbf{( F}^{\circ}\right)\end{array}$ & $\begin{array}{c}\text { Re-entry/ } \\
\text { Soak- } \\
\text { through } \\
\left(\mathbf{F}^{\circ}\right)\end{array}$ \\
\hline \multirow{5}{*}{ I } & AFRSI OML & 38.2 & 1,676 \\
\cline { 2 - 4 } & CRI batting & 34.7 & 1,663 \\
\cline { 2 - 4 } & AFRSI IML & -153.8 & 345.3 \\
\cline { 2 - 4 } & RTV-560 & -154.1 & 344.5 \\
\cline { 2 - 4 } & TEEK & -154.2 & 344.1 \\
\cline { 2 - 4 } & PDL-1034 & -240.6 & 246.4 \\
\cline { 2 - 4 } & Lord 212TM & -422.9 & 177.0 \\
\cline { 2 - 4 } & Al 2219 & -423.0 & 177.0 \\
\hline \multirow{5}{*}{ II } & HFRSI & 35.42 & 542.6 \\
\cline { 2 - 4 } & FRSI & 35.15 & 539.6 \\
\cline { 2 - 4 } & RTV-560 & 18.41 & 428.4 \\
\cline { 2 - 4 } & TEEK & 18.32 & 427.7 \\
\cline { 2 - 4 } & PDL-1034 & -162.5 & 249.1 \\
\cline { 2 - 4 } & Lord 212TM & -422.8 & 141.1 \\
\cline { 2 - 4 } & Al 2219 & -423.0 & 141.1 \\
\hline \hline
\end{tabular}

\section{PANDA2 Program}

PANDA2 is an analysis and optimization program developed by David Bushnell [9] that is capable of analyzing and optimizing flat or radially symmetric panels stiffened with combinations of internal and external stringers, ring frames, and grids of various cross-sections. PANDA2 enables the analysis by using a combination of relatively simple models to capture individual failure modes. Possible failure modes include: yielding, and general stiffener and skin pocket buckling. Optimization is performed using gradientbased algorithms [10], with mechanical failure constraints and user-defined geometric constraints. Feasibility is determined using constraint margins, with 
the convention that negative margins are infeasible. Mechanical failure constraints are defined such that maximum violation corresponds to a margin of -1 . Geometric margins are evaluated using a user-defined inequality, and may in fact be much lower than -1 in various regions of design space.

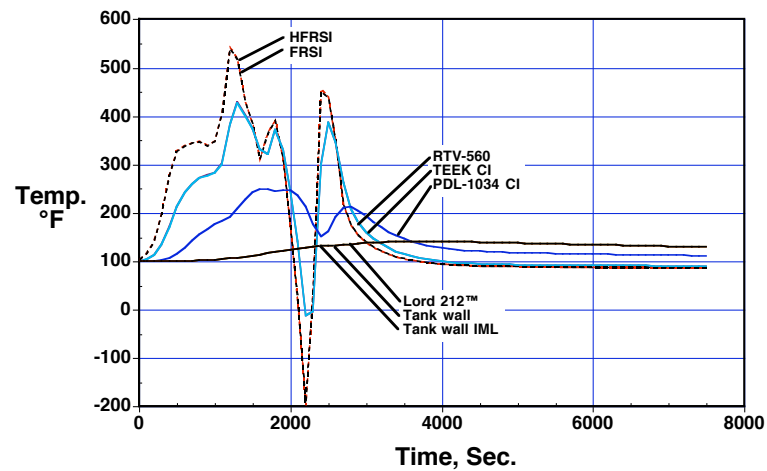

Figure 13. Temperature results at the upper surface of each layer of Concept II with FRSI TPS for the re-entry/soak-through case.

PANDA2 provides a single deterministic optimum design, and cannot directly calculate the probability of failure (POF) of a given design, making reliability optimization difficult. A new optimization algorithm, DIRECT $[9,10]$, was introduced in order to facilitate reliability optimization, broadening the range of design problems to which PANDA2 may be applied. In addition, MCS and response surface approximation [11] were used for efficient reliability analysis.

The critical margins $\left(\mathrm{M}_{1}, \mathrm{M}_{2}\right)$ are defined as the most negative margin (that was associated with the most violated constraint) evaluated at each position on the shell. The critical margin, $\mathrm{M}_{1}$, is evaluated either between the ring frames, if the ring frames are present, or else at the middle of the panel. The critical margin at the ring frames is $\mathrm{M}_{2}$. If no ring frames are present, $\mathrm{M}_{2}$ is undefined and was assumed to be equal to zero.

\section{DIRECT Algorithm}

DIRECT, a global sampling optimization algorithm, was selected over gradient-based optimization because the designs space has many local optima. Additionally, changing critical constraints and imperfection-induced discontinuities caused sharp variations in the critical margin surface.

DIRECT is a modified Lipschitzian optimization algorithm [7, 8] that begins by evaluating the function to be minimized at the center of the design space. The algorithm then divides the space into thirds based on evaluations of the objective function, and chooses potentially optimum boxes for further division based on the objective function and the size of the box. This division operation is repeated, as illustrated in Figure 14. Given infinite iterations, DIRECT will evaluate every point in the design space. A more detailed explanation of this procedure is given in references [7] and [8].

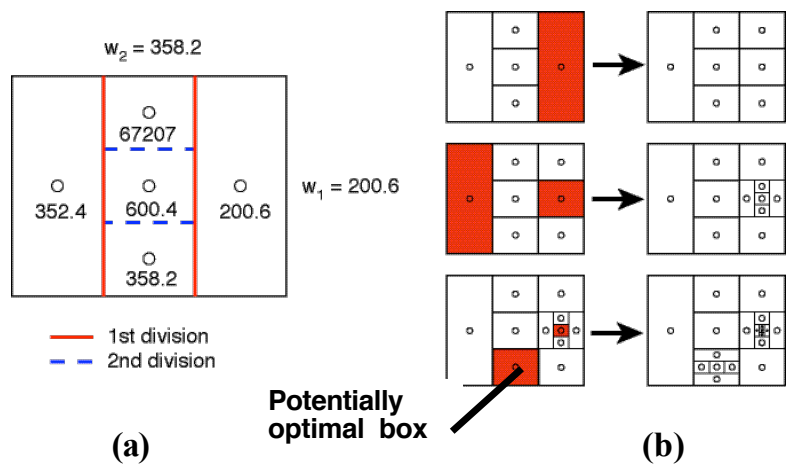

Figure 14. (a) $1^{\text {st }}$ iteration of DIRECT which shows windowing for a 2-dimensional example, the Goldstein-Price function and (b) further iterations.

\section{Implementation}

A penalty function was used for infeasible designs. A more detailed description of the implementation of the penalty function is in reference [12]. Ideally, this penalty, $W_{p e n}$, is the increase in weight, $W$, required to attain feasibility. To eliminate designs with large negative margins, a penalty function with a quadratic term was used. The penalty function also contains a linear term to force the optimum to favor the feasible domain over slightly infeasible points. Thus, a suitable penalized weight function is of the form

$$
W_{p e n}=W\left[1+\square_{1}\left(\square_{1} \mathbf{M}_{1}^{2}+\square_{1} \mathbf{M}_{1}\right)+\square_{2}\left(\square_{2} \mathbf{M}_{2}^{2}+\square_{2} \mathbf{M}_{2}\right)\right]
$$

where $\square$ and $\square$ are penalty parameters, and $\square$ is a switch, equal to 0 when $M_{i}$ is greater than 0 (feasible) and 1 when $M_{i}$ is less than 0 (infeasible).

To simplify the problem, the penalty parameters $\square$ and $\square$ were assumed to be, $\square_{1}=\square_{2}=\square$ and $\square_{1}=\square_{2}=$ $\square$. It is sufficient and rather simple to find $\square$ and $\square$ by trial and error such that the best designs are either feasible or nearly so. Reasonable values for the types of problems used in this study are $\square=4$ and $\square=1$.

\section{$\underline{\text { Reliability Analysis }}$}

MCS was used in the reliability analysis because this simulation technique is easy to implement, robust, and accurate with sufficiently large samples. However, MCS requires a large number of analyses to obtain an accurate estimate of small failure probabilities. Response surface approximations were used to reduce the number analyses, by fitting a closed-form approximation to the limit state function. Response surface approximations usually fit low order polynomials to the structural response in terms of random variables. Qu et al. [13] developed a global

\section{American Institute of Aeronautics and Astronautics}


space of design and random variables to substantially reduce the number of response surface approximations.

\section{Aluminum Tank Optimization}

The tank barrel optimized was an aluminum cylinder (Al 2219), stiffened externally with J-shaped ring frame stiffeners, and internally with a blade-shaped isogrid oriented circumferentially as shown in Figure 15. The material properties for Al 2219 are listed in Table 5. The length, $\mathrm{L}_{1}$, of the tank barrel was 300 in., and the radius, r, was 160 in. Using symmetry, it sufficed to model half of a cylindrical tank, spanning $180^{\circ}$. The tank was subjected to both internal pressure and axial compression. The pressure partially relieved the influence of buckling due to axial compression, an effect known as pressure stabilization. The first load set was a proof-pressure of 35 psi with no axial load. The second load set was due to ground handling with an operating pressure of 5 psi and an axial compression load of $1,000 \mathrm{lbs}$./in. Thermal loads were not considered since the tank was assumed to be at isothermal conditions and the tank material was assumed to be isotropic.

Table 5. Al 2219 material properties and coefficients of variation.

\begin{tabular}{ccccc}
\hline \hline Var. & $\begin{array}{c}\text { Density } \\
(\square) \\
\left(\mathbf{l b s .} / \text { ft. }^{3}\right)\end{array}$ & $\begin{array}{c}\text { Young's } \\
\text { Modulus } \\
(\boldsymbol{E}) \\
(\mathbf{p s i})\end{array}$ & $\begin{array}{c}\text { Poisson's } \\
\text { ratio } \\
(\square)\end{array}$ & $\begin{array}{c}\text { Allow. } \\
\text { Stress } \\
\left(\square_{\mathrm{a}}\right) \\
(\mathbf{p s i})\end{array}$ \\
\hline Mean & 0.1030 & $0.107 \times 10^{8}$ & 0.34 & $0.58 \times 10^{5}$ \\
\hline COV & - & 0.03 & 0.03 & 0.05 \\
\hline \hline
\end{tabular}

The optimization scheme varied the isogrid spacing, the isogrid blade height, and the thicknesses of the skin and isogrid blades. The ring frame geometry was considered fixed and listed in Table 6 . The optimization was subject to PANDA2 failure constraints with the objective of minimizing the structural weight of the tank.

The PANDA2 analysis was based on a procedure developed by Lamberti et al. [14], for the optimization of a similar aluminum tank with the ring frame geometry removed. The lower and upper bounds for optimization are given in Table 7 along with a design obtained by the internal optimizer in PANDA2.

Table 6. Fixed tank geometry for the ring frame.

\begin{tabular}{cc}
\hline \hline Variable & $\begin{array}{c}\text { Fixed geometry } \\
\text { (in.) }\end{array}$ \\
\hline Spacing $\left(\mathrm{b}_{\text {ring }}\right)$ & 113.9 \\
\hline Base $\left(\mathrm{b}_{2}\right)$ & 0.4 \\
\hline Web height $\left(\mathrm{h}_{\text {ring }}\right)$ & 2.0 \\
\hline Flange $(\mathrm{w})$ & 0.48 \\
\hline Base thickness $\left(\mathrm{T}_{3}\right)$ & 0.03 \\
\hline Web thickness $\left(\mathrm{T}_{4}\right)$ & 0.06212 \\
\hline Flange thickness $\left(\mathrm{T}_{5}\right)$ & 0.07952 \\
\hline \hline
\end{tabular}

Table 7. Variable tank geometry with bounds and PANDA2 optimum design.

\begin{tabular}{c|cccc}
\hline \hline \multicolumn{2}{c}{ Variable } & $\begin{array}{c}\text { Lower } \\
\text { bound } \\
\text { (in.) }\end{array}$ & $\begin{array}{c}\text { Upper } \\
\text { bound } \\
\text { (in.) }\end{array}$ & $\begin{array}{c}\text { PANDA2 } \\
\text { results } \\
\text { (in.) }\end{array}$ \\
\hline \multirow{3}{*}{ Isogrid } & Spacing $\left(\mathrm{b}_{\text {grid }}\right)$ & 5 & 15 & 10.71 \\
\cline { 2 - 5 } & Height $\left(\mathrm{h}_{\text {grid }}\right)$ & 1 & 5 & 2.049 \\
\cline { 2 - 5 } & Thickness $\left(\mathrm{T}_{2}\right)$ & 0.08 & 0.25 & 0.0989 \\
\hline \multicolumn{2}{c}{ Skin thickness $\left(\mathrm{T}_{1}\right)$} & 0.03 & 0.25 & 0.1261 \\
\hline \multicolumn{2}{c}{ theight } & - & - & $5,196 \mathrm{lbs}$. \\
\hline \hline
\end{tabular}

\section{DIRECT Optimization}

A feasible optimum design was obtained using DIRECT with $\square=4$ and $\square=1$ and is listed in Table 8 with results for other penalty parameters. The range of geometries for the designs with a penalized weight similar to the optimum (near-optima) are given in Table 9 for the case of $\square=4$ and $\square=1$. These designs are fairly wide-spread around the design space. Approximately 1,000 function evaluations were needed to converge to the design in Table 10 that was 4 percent lighter than the PANDA2 optimum. DIRECT optimization did not evaluate any designs similar to the optimum determined in PANDA2, although additional iterations of DIRECT would eventually reveal designs similar to the PANDA2 optimum.

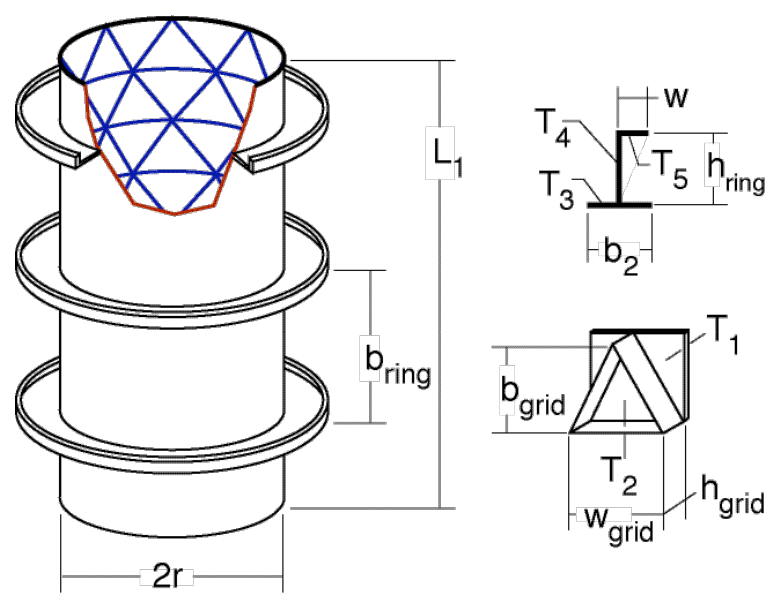

Figure 15. The basic tank barrel geometry for an isogrid stiffened aluminum cryogenic tank with exterior ring frames.

Accurate critical margin response surfaces were constructed to evaluate the reliability of a design point. The uncertainty in the material properties was represented by three random variables, two for elastic properties (modulus of elasticity, E, and Poisson's ratio, $\square)$ and one for the allowable stress $\left(\square_{a}\right)$, which were assumed to be normally distributed and uncorrelated. The mean values and coefficients of variation of the uncertainties in material properties are shown in Table 5. The four design variables $\left(b, h, T_{I}\right.$ 
and $T_{2}$ ) also have randomness in them due to manufacturing uncertainties and were assumed to be uniformly distributed. Table 11 shows the percentage variation of the random design variables. The data in Table 11 are obtained based on rough estimates, and are intended for illustration purposes only.

Table 8. DIRECT optimum designs with various penalty coefficients.

\begin{tabular}{|c|c|c|c|c|c|}
\hline \multicolumn{2}{|c|}{ Penalty } & \multirow{2}{*}{$\begin{array}{c}\text { Weight } \\
\text { (lbs.) }\end{array}$} & \multirow{2}{*}{$\begin{array}{c}\text { Penalized } \\
\text { weight } \\
\text { (full tank) } \\
\text { (lbs.) }\end{array}$} & \multirow{2}{*}{$\mathbf{M}_{1}$} & \multirow{2}{*}{$\mathbf{M}_{2}$} \\
\hline$\square$ & $\square$ & & & & \\
\hline 1 & 0 & 4,764 & $4,821.6$ & 0.197 & -0.110 \\
\hline 2 & 0 & 4,724 & $4,813.1$ & 0.179 & -0.097 \\
\hline 3 & 0 & 4,760 & $4,834.6$ & 0.190 & -0.072 \\
\hline 4 & 0 & 4,944 & $4,945.1$ & 0.245 & -0.007 \\
\hline 4 & 1 & 4,970 & $4,970.0$ & 0.177 & 0 \\
\hline
\end{tabular}

Table 9. Range of design variables for designs with $W_{\text {pen }}$ within 200 lbs. of optimum full tank weight.

\begin{tabular}{ccccc}
\hline \hline Quantity & $\begin{array}{c}\text { b } \\
\text { (in.) }\end{array}$ & $\begin{array}{c}\mathbf{h} \\
\text { (in.) }\end{array}$ & $\begin{array}{c}\mathbf{T}_{\mathbf{1}} \\
\text { (in.) }\end{array}$ & $\begin{array}{c}\mathbf{T}_{\mathbf{2}} \\
\text { (in.) }\end{array}$ \\
\hline Low & 5.021 & 1.617 & 0.0936 & 0.1197 \\
\hline High & 6.187 & 2.012 & 0.1104 & 0.1291 \\
\hline \% of bounds & $11.7 \%$ & $9.9 \%$ & $9.9 \%$ & $4.3 \%$ \\
\hline \hline
\end{tabular}

Table 10. Comparison of DIRECT $(\square=4, \square=1)$ and PANDA2 optima.

\begin{tabular}{ccc}
\hline \hline \multirow{2}{*}{ Variable } & \multicolumn{2}{c}{ Method } \\
\cline { 2 - 3 } & $\begin{array}{c}\text { DIRECT } \\
\text { optimum }\end{array}$ & $\begin{array}{c}\text { PANDA2 } \\
\text { optimum }\end{array}$ \\
\hline $\mathrm{b}$ & $5.043 \mathrm{in}$. & $10.71 \mathrm{in}$. \\
\hline $\mathrm{h}$ & $1.617 \mathrm{in}$. & $2.049 \mathrm{in}$. \\
\hline $\mathrm{T}_{1}$ & $0.0957 \mathrm{in}$. & $0.0986 \mathrm{in}$. \\
\hline $\mathrm{T}_{2}$ & $0.1197 \mathrm{in}$. & $0.1261 \mathrm{in}$. \\
\hline $\mathrm{Weight}_{\mathrm{M}}$ & $4,970 \mathrm{lbs}$. & $5,196 \mathrm{lbs}$. \\
\hline $\mathrm{M}_{1}$ & 0.239 & $-9.95 \times 10^{-6}$ \\
\hline $\mathrm{M}_{2}$ & 0.0 & 0.0189 \\
\hline \hline
\end{tabular}

Table 11. Percentage variation of the random design variables around design value.

\begin{tabular}{ccccc}
\hline \hline & $\mathbf{b}$ & $\mathbf{h}$ & $\mathbf{T}_{\mathbf{1}}$ & $\mathbf{T}_{\mathbf{2}}$ \\
\hline$\%$ Variation & $\pm 1 \%$ & $\pm 2 \%$ & $\pm 4 \%$ & $\pm 4 \%$ \\
\hline \hline
\end{tabular}

Response surface approximation approaches were employed to fit response surfaces to the most critical safety margins for the designs centered around the nearoptima selected based on Latin Hypercube sampling and the variabilities. As in the deterministic optimization, isogrid panels were analyzed using PANDA2 with constraint safety factors adjusted to 1.0. The most critical margins of the two load cases were then extracted. Polynomial response surface approximations were fitted to the worst safety margins in terms of random variables. POF for the panel system and each load case were calculated by performing MCS on the polynomial response surfaces [13]. This calculation was performed for the PANDA2 and DIRECT optima given in Table 10, with response surface statistics given in Table 12, and POF given in Table 13. Both points were modeled with acceptable accuracy. Further investigation of the design space for feasible solutions was not necessary since the DIRECT design meets the very strict POF constraint, at most 1 in $10^{8}$.

Table 13. POF calculated by MCS.

\begin{tabular}{ccccc}
\hline \hline Method & $\begin{array}{c}\text { No. of } \\
\text { samples } \\
\text { in MCS }\end{array}$ & $\begin{array}{c}\text { POF at } \\
\text { mid-ring } \\
\text { frame }\end{array}$ & $\begin{array}{c}\text { POF at the } \\
\text { ring frame }\end{array}$ & $\begin{array}{c}\text { System } \\
\text { POF }\end{array}$ \\
\hline $\begin{array}{c}\text { DIRECT } \\
\text { optimum }\end{array}$ & $1 \times 10^{9}$ & 0 & 0 & 0 \\
\hline $\begin{array}{c}\text { PANDA2 } \\
\text { optimum }\end{array}$ & $10 \times 10^{6}$ & 0 & $394 \times 10^{-6}$ & $394 \times 10^{-6}$ \\
\hline \hline
\end{tabular}

\section{COMBINED RESULTS}

The results from the thermal sizing study and structural study are combined in Table 14. An efficient and minimum areal weight for a barrel section is shown in Table 14 for the windward (Concept I) and leeward (Concept II) sides of the vehicle. The windward side of the vehicle is much heavier (34.2 percent) than the leeward side due to the additional TPS required to withstand the high heat flux load on the windward side during re-entry. The additional TPS, however, reduced the amount of CI, since the TPS acts as a cryogenic insulator.

To further minimize the weight for the whole barrel section, similar thermal and structural sizing studies would be required around the circumference of the barrel. Plug thermal sizing around the circumference would enable the tailoring of TPS from the windward side to the leeward side of the vehicle. Additionally, the tank structure would be separated into four sections such as the crown, two side panels, and keel in a more detailed structural sizing study.

Table 12. ARS approximation to the worst margin using Latin Hypercube sampling.

\begin{tabular}{ccccc}
\hline \hline \multirow{2}{*}{ Quantity } & \multicolumn{2}{c}{ Cubic ARS } & \multicolumn{2}{c}{ Quadratic ARS } \\
\cline { 2 - 5 } & $\mathbf{M}_{\mathbf{1}} \mathbf{f i t}$ & $\mathbf{M}_{\mathbf{2}}$ fit & $\mathbf{M}_{\mathbf{1}}$ fit & $\mathbf{M}_{\mathbf{2}}$ fit \\
\hline $\mathrm{R}_{\text {adj. }}^{2}$ & 0.9999 & 0.9377 & 0.9085 & 0.9998 \\
\hline RMSE predictor & 0.000253 & 0.0416 & 0.0261 & 0.000603 \\
\hline Mean of response & 0.6929 & 1.2812 & 0.4601 & 0.1251 \\
\hline \hline
\end{tabular}


Table 14. Combined areal weight results from the thermal and structural sizing studies.

\begin{tabular}{|c|c|c|c|c|c|}
\hline Concept & $\begin{array}{c}\text { Tank } \\
\text { weight from } \\
\text { DIRECT } \\
\text { (lbs./in.') }\end{array}$ & $\begin{array}{c}\text { CI } \\
\text { weight* }^{2} \\
\left.\text { (lbs./in. }^{2}\right)\end{array}$ & $\begin{array}{c}\text { TPS } \\
\text { weight }^{\dagger} \\
\text { (lbs./in. }^{2} \text { ) }\end{array}$ & $\begin{array}{c}\text { Total } \\
\text { insulation } \\
\text { weight } \\
\text { (lbs./in. }{ }^{2} \text { ) }\end{array}$ & $\begin{array}{c}\text { Combined } \\
\text { weights } \\
\left.\text { (lbs./in. }{ }^{2}\right)\end{array}$ \\
\hline I & 0.01648 & 0.001207 & 0.009917 & 0.01112 & 0.02760 \\
\hline II & 0.01648 & 0.002509 & 0.001584 & 0.004093 & 0.02057 \\
\hline
\end{tabular}

\section{CONCLUDING REMARKS}

Thermal and structural analysis tools were developed for the sizing of insulation and structural geometry of integrated cryogenic propellant tank concepts for a reusable launch vehicle (RLV). These tools were used to size the thickness of the cryogenic insulation (CI), insulation thickness for thermal protection system (TPS), and isogrid stiffener geometry and skin thickness of an aluminum 2219-T87 tank wall. The analytical studies and results described in this paper are a portion of the basic information required for the development of light-weight reusable integrated cryogenic propellant tanks.

A thermal sizing study to determine the thickness of the insulation was successfully performed using ABAQUS, a commercial nonlinear finite element method (FEM) analysis code for separate but related analytical studies for ground-hold and re-entry/soakthrough conditions. The nonlinear transient heat transfer analyses used the temperature and pressure dependent thermal material properties to determine the through-the-thickness temperatures of two concepts. Concept I employed conformable reusable insulation (CRI) TPS for the windward side while Concept II, the leeward side, used flexible reusable surface insulation (FRSI) TPS. Concept I used approximately half of the CI that Concept II required but weighed 34.2 percent more in combined insulation weight. The increased weight was due to the additional TPS required to resist re-entry aerothermal heating, while Concept II had the thinnest layer of FRSI possible. The prevention of frost accumulation on the external surface for the ground-hold case dominated the sizing for both concepts.

Alternative structural designs were obtained by using the DIRECT optimizer to explore the design space, allowing for more accurate reliability optimization. The design obtained from DIRECT was 4.3 percent lighter than the PANDA2 deterministic design and had a near zero probability of failure compared to the $364 \times 10^{-6}$ probability of failure for the PANDA2 design.

The methods and analytical tools developed for these studies provided an efficient means to analyze, size, and evaluate candidate-integrated designs for future
RLVs. The thermal sizing study established a method for sizing the thickness of insulation layers using FEM. The structural sizing study developed an optimization method that produced more robust alternate structural designs than deterministic optimization methods by using reliability optimization techniques in conjunction with deterministic optimization techniques.

\section{ACKNOWLEDGMENTS}

The authors would like to thank the following for their technical discussion and suggestion: Kamran Daryabeigi of NASA Langley Research Center, Kirk Svartstrom, Peter Duong, and Guillermo Mas of the Boeing Corporation, and Arunkumar Satyanarayana of Swales Aerospace.

\section{REFERENCES}

1. Freeman, Jr., D. C., Stanley, D. O., Camarda, C. J., Lepsch, R. A., Cook, S. A., "Single-Stage-ToOrbit-A Step Closer," Presented at the 45th Congress of the International Astronautical Federation (IAF), October 1994, IAF 94-V3.534.

2. NASA, "Access to Space Study Final Report," NASA Headquarters, Washington DC, July 1993.

3. Weiser, E. S., Johnson, T. F., St. Clair, T. L., Echigo, Y., Kaneshiro, H., Grimsley, B.W., "Polyimide Foams for Aerospace Vehicles", Journal of High Performance Polyimides, Volume 12 (2000), pp. 1-12.

4. Myers, D. E. Martin, C. J., Blosser, M. L., "Parametric Weight Comparison of Advanced Metallic, Ceramic Tile, and Ceramic Blanket Thermal Protection Systems (TPS)," NASA Technical Memorandum L-17651, August 1997.

5. Williams, S. D., Curry, D. M., "Thermal Protection Materials: Thermal Property Data," NASA Reference Publication 1289, December 1992.

6. Smeltzer, S. S., Waters, W. A., "Nonlinear Thermal Analysis of a Liquid Hydrogen Tank Wall," Joint Army-Navy-NASA-Air Force (JANNAF) 2003 Conference, Colorado Springs, CO, Dec. 2003.

7. Finkel, D. E., "DIRECT Optimization Algorithm User Guide," http://www4.ncsu.edu:8030/ $\sim$ definkel/research/DirectUserGuide_pdf.pdf 
8. Jones D. R., Pertunen C. D., Stuckman B. E, "Lipschitzian Optimization Without the Lipschitz Constant," Journal of Optimization Theory and Application, Vol. 79, No. 1, 1993, pp 157-181.

9. Bushnell, D. "PANDA2 - Program for Minimum Weight Design of Stiffened, Composite, Locally Buckled Panels," Computers and Structures, Vol. 25, No. 4, 1987, pp 469-605.

10. Vanderplaats, G. N., "ADS - A Fortran Program for Automated Design Synthesis - Version 1.10," NASA CR 177985, 1985.

11. Myers, H. R., Montgomery, D. C., Response Surface Methodology, Wiley, New York, 1995.

12. Singer, T. N., Qu, X., Haftka, R. T., "Global Optimization of a Composite Tank Structure Using the DIRECT Algorithm," ASC Paper 249, Proceedings of the American Society for Composites $18^{\text {th }}$ Technical Conference, Gainesville, FL, Oct. 20-23, 2003.

13. Qu, X., Venkataraman, S., Haftka, R. T., and Johnson, T. F., "Deterministic and Reliabilitybased Design of Composite Laminates for Cryogenic Environments," scheduled to be published in September, 2003 by AIAA Journal.

14. Lamberti, L., Venkataraman, S., Haftka, R. T., and Johnson, T. F., "Preliminary design optimization of stiffened panels using approximate analysis models," International Journal for Numerical Methods in Engineering, Vol. 57, No. 10, 2003, pp. 1351-1380. 